\title{
Assessment of College Students' Preference on the Usage of Google Drive as a Learning Platform: An Empirical Evidence
}

\author{
Mahmud Tukur Abubakar \\ School Of Business Education \\ Federal College of Education (Tech) Gombe, Nigeria \\ E-mail: abubakarmahmudt542@gmail.com \\ Tel:+2348036939178
}

\begin{abstract}
This research assessed College Students preference on the Usage of Google Drive as a learning platform in north-east Nigeria. The study had three objectives, three research questions and three null hypotheses. Descriptive survey research design was used for the study. The population of the study was 263 three hundred level business education students in north-eastern Nigeria. Four rating scale structured questionnaire titled “College students' preference of Google Drive (CGD”) was used for data collection. The instrument was validated by experts from the Faculty of Technology Education, Abubakar Tafawa Balewa University Bauchi. The researcher personally administered the instrument assisted by 3 research assistants. Data collected was analyzed using Mean and standard deviation statistical tools to answer the research questions. The result of the study reveals that students used Google Drive for assignments, study and downloading of materials. Based on the outcome of the study, it was concluded that Google Drive platform provide undergraduate business education students with opportunities to enhance and assess current educational information. It was recommended that lecturers and all stakeholders who handle business education courses should be encourage to adopt the use of Google Drive as a learning platform, The business education students should utilize and exploit maximally the opportunities provided by the use of Google Drive as a learning platform for learning activities with the help of their lecturers etc. in addition useful suggestions for further research are equally made.
\end{abstract}

Keywords: College Students', Usage of, Google Drive, Learning Platform. Nigeria.

\section{Background to the Study}

Social networks are becoming an integral part of our lives. Students are spending much time on social network and are considered the largest category that uses such application (Heyyam, 20I4). The impact of the Internet on education is an important issue that has caught educators' attention in recent years. Several recent studies confirmed that online interaction might provide learners flexibility, stimulate more innovative ideas, and facilitate learning. For example, Dietz-Uhler and BishipClark (200I) found that face-to-face discussions preceded by Computer-network Communications (CNC) were perceived to be more enjoyable and could include a greater diversity of perspectives than the face-to-face discussions not proceeded by $\mathrm{CNC}$.

Hammond (2000) argued that there is a particular educational value in a communicative approach to online discussions. Social network has exploded as a category of online communication where people create content, share it, bookmark it and network at impressive rate. Due to Network usage ease of use, speed and reach, social network is fast changing the public conversation in society and setting trends and agenda in topics that range from the environment and politics to technology and the entertainment industry. Martn (2008) and Lusk, (2010) share the same concept of social network. The scholars maintained that social network is the use of Facebook, Blogs, Twitter, Google drive, My Space and Linked-In etc. for the purpose of communication, sharing photos as well as videos.

Google Drive is a file storage and synchronization service created by Google (Pichai, 20I2). It allows users to store files in the cloud, synchronize files across devices, and share files. Google Drive encompasses Google Documents, Sheets and Slides, an office suite that permits collaborative editing of documents, spreadsheets, presentations, drawings, forms, and more. The Google Drive was made available for free to all Google Apps for Education users have unlimited storage and support for individual files up to $5 \mathrm{~TB}$ in size, with full encryption. Users can search for images by describing or naming, what is in them. For example, a search for "mountain" returns all the photos of mountains, as well as any text documents about mountains

Google tools can be easily used even without having an exclusive Google account. Students can start participating in the collaborating (Group work) activities designed using Google tools with a Google drive. It is also possible to use the full suite of Google application from the Google Drive, where one can create presentations, spreadsheets, documents etc. sometimes similar to Microsoft office applications (Garnier 2013). Google Drive has the share function which allows for uploading and dawnloading of the documents to anyone around the globe with a simple share link. Incidentally, the students can collaborate with the entire class or tutorial group, with the aid of email addresses in one master document at the start of the semester to ease future invitations. 
Google Drive has a potential of improving the teaching and learning processes as they contain useful applications. Learning through mobile devices can occur anywhere and anytime (Brown, 2008). It is very easy to create a more useful learning environment if students either have a Computer or some other types of communication devices. Also, they are cheap when compared to other ICTs, and everyone can afford them (Kizito 2012). Hoppe (2009) states that students can read materials such as e-books and can watch lecture on mobile phones. According to Kafyulilo (2012), downloading feature on Google Drive can be used to get various kinds of materials and video.

\section{Statement of the Problem}

Teaching and learning is all about communication between the teacher and the learner or between the learner and the learning materials which involves giving and receiving of information. Research have shown that technologies enhance teaching and learning by providing opportunities through offering better access to relevant articles, teaching and learning materials(Brown $\&$ Adler, 2008). It enables the effectiveness of storing and sorting of information, and can offer new fast ways of communication; even with the obvious and enormous advantages that comes with the use of social media in teaching and learning which are the main functions of Google Drive as a platform.

Despite the availability and accessibility as a result of internet connectivity of Google drive, student's embracement to the technology is nothing to write home about. So many researches had been conducted on blogger (Prensky 2004), YouTube, (Peter D. 2008) Facebook (Roreger, \& Schmidt, 2012), Whatsapp (Albergottiet al 2014), and other internet related field, but little or no study has been conducted on Google drive in Nigerian context. It is against this background that this study is set out to assess the Undergraduate business education students' preference toward the use of Google drive as a learning platform in North East Nigeria.

The formulated the following objectives/questions in order to find answers to them at the end of the study. Objectives of the study

The main objective of this study is to assess College students' preference on the usage of Google drive as a learning platform in North East Nigerian. Specifically the study intends to achieve the following objectives:-

- To determine the College students' preference in the use of Google drive as an assignment/group work platform for learning in North-east Nigeria.

- To ascertain the College students' preference in the use of Google drive as a platform for study in North-east Nigeria.

- To assess College students' preference in the use of Google drive as a platform for upload/download of files in Northeast Nigeria.

\section{Research Questions}

- In line with the objectives, the study was guided by the following research questions:

- What is the College students' preference on the use of Google drive as an assignment/group work platform for learning in north- east Nigeria?

- To what extent is the College students' preference on the use of Google drive as a platform for study in north east Nigeria?

- What is College students' preference on the use of Google drive as a platform for upload/download of files in north east Nigeria?

\section{Theoretical Framework/Literature Review}

The study adapted Technology Acceptance Model (TAM) developed by Davis in I985, in this scheme; Davis (I985) suggested that user's motivation can be explained by three factors: Perceived ease of use, Perceive usefulness, and attitude towards us ing the system. He assumed that the attitude of a user towards a system remained a major determinant of whether the user will actually use or reject the system. The attitude of the user, in turn, was considered to be influenced by three major beliefs; perceive usefulness and perceived ease of use, with perceive ease of use having direct influence on perceived usefulness. Finally, both these belief were assumed to be directly influenced by the system design characteristics.

During future experimentation stages, Davis (1985) improves his model to include other variable and modify the relationship that he initially formulated. Similarly, other researchers apply, and propose several additions to the Technology Acceptance Model (TAM). Actively, TAM changes into a leading model in explaining and predicting system use. In fact, TAM has become so popular that it has been cited in most of the researches that deals with user's acceptance of technology (Lee, Kason, \& Larsen, 2003)

Nevertheless, some researchers' assertion that TAM may have elaborate more easy and speedy research, such that less consideration has been given to the real problem of technology acceptance (Lee, Kason \& Lasen 2003). Today, researches on technology suitability is still ongoing, and thus an understanding of the expectations, powers, and borders of the Technology Acceptance model is crucial for anyone willing to study user acceptance of technology. 
TAM has been broadly applied to a range of technologies and users. It provides evidence on how external variables influence intention to use, belief and attitude. Consequently, in the present study TAM is utilized as a framework to investigate what criteria determine usage of Google Drive in an educational context. This theory is chosen because it is widely applied in the research on technology usage in many different contexts. Underpinned by the framework of the TAM, this study will estimate the postulated TAM in the context of Google Drive with a focus on the validation of the relationships involved specifically, perceived usefulness, ease of use, intention to use and actual use. The findings will reveal the students' perceptions of the importance of Google Drive, their actual use of cloud computing and their intention to use cloud computing in the future within a school setting.

TAM has been widely used to test the acceptance of e-learning technologies. Studies that use TAM have addressed perceived usefulness, ease of use, attitude, behavioral intention, and system usage as the major determinants that predict the acceptance of a new technology. In this study, perceived ease of use is defined as the degree to which the user believes that using Google Drive would be free of effort, and perceived usefulness is defined as the degree to which the user believes that using Google Drive would enhance his/her learning performance (Davis, 1989). According to Davis (I989), perceived usefulness and perceived ease of use are important factors that influence the attitude of individuals toward a particular technology. The TAM posits that perceived ease of use and perceived usefulness have a direct effect on the attitude toward the use of a technology, and perceived ease of use has a positive effect on perceived usefulness. Attitude is defined as the degree to which a user is interested in using the system, and attitude toward the system determines behavioral intentions, which, in turn, lead to actual system usage. A number of researchers have applied TAM to explain user acceptance of collaborative systems.

Therefore, this research work examine the attitude of business education student in using Google Drive as a new technology to enhancing learning in which the Technology acceptance theory is being used. The relationship between this theory and the research work is on the ease of use Google Drive application and perceived usefulness towards Google Drive which make them having common characteristic with the theory as proposed by Davis (I985) and as relates to this research work is depicted below:

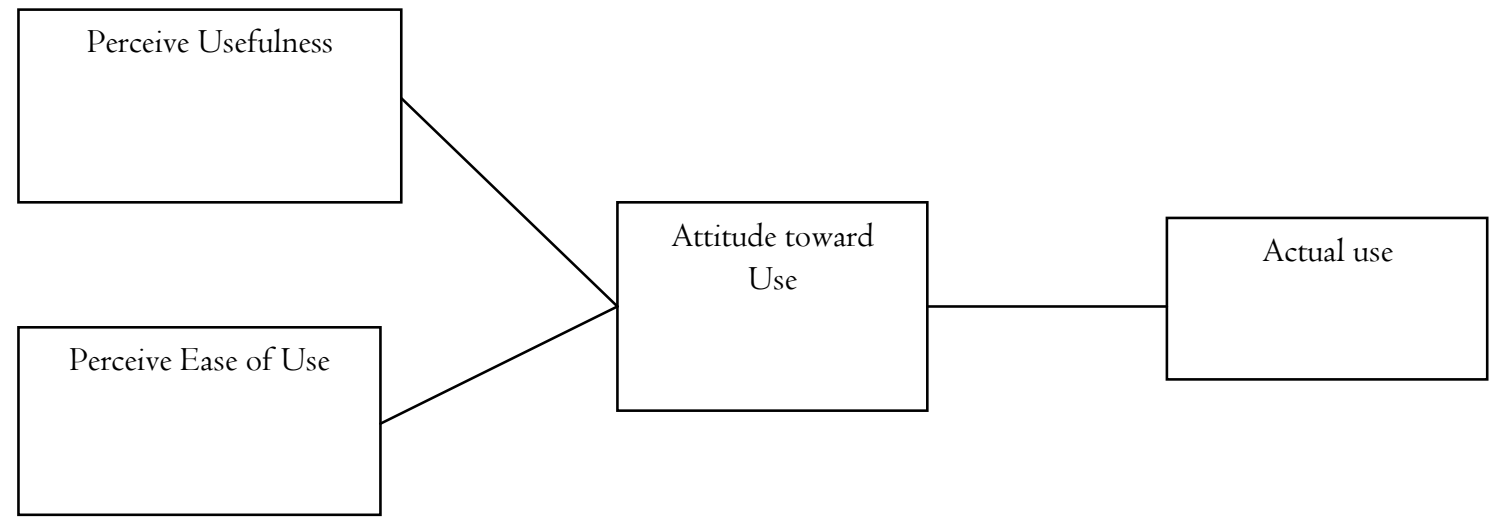

Figure I. Original Technology Acceptance Model Adopted from Davis (1970)

\section{Roles of Google Drive}

A greater reliance on technology alters the student-teacher interaction. Instruction through computers can give students more control over their learning environments and access to a wider range of materials to use in the learning process (Ransdall, 2002). Additionally, for computer-assisted learning to be effective, the instructors need to put careful thought into their lesson plans. The level of student understanding must be taken into consideration. "Instructional software makes the human teacher more important, rather than less" (Ransdall, 2002). In order to fully understand how computers contribute to learning, there has to be an investigation into how the use of a computer controls the behavior of both students and teachers (Karasavvidis et. al., 2003). Among many technologies, Google Drive is a learning tool which helps to implement the learner-centered approach in a collaborative learning environment. According to Oxnevad (2013), document sharing and comments provide students with opportunities to receive immediate feedback.

Google Drive is easy and fast, the tool is well-suited for facilitating digital writing workshops that combine peer editing with cooperative grouping and small group fine-tuned writing instruction. Sharp (2009) suggests that this collaborative editing tools allow a group of individuals to edit a document simultaneously while they can view the changes made by others in real time. This special feature makes Google Drive a powerful program that can facilitate collaborative writing in the language classroom. By sharing documents and keeping them online, students can access them anytime. Chinnery (2008) states that Google Drive is a productive tool where learning activities can be designed differently and creatively. For instance, an instructor 
might post a text, intentionally replete with errors, for learners to correct. Likewise, learners can easily peer-edit, as this program leaves an editing trail. Another option is chain storytelling, where an instructor begins a story which each learner contributes to in turn. Moreover, this tool is useful in group projects in general. Google Drive allows individuals to work on a common task without restrictions often imposed by traditional face-to-face contacts (Conner, 2008;Perron\& Sellers, 20II).

The most useful delivery method provided by Google Drive is that instructors can make a copy for each student which automatically adds a copy of the assignment to the student's Google Drive (Amanda and Katie, 20I5). However, in 2015 the grading system provided by Classroom was not as sophisticated as other learning management systems like Blackboard or Moodle (Shiohara et al., 2014).Moreover, there were no comprehensive grade book, test, or quiz features. Additionally, there are some privacy concerns since the actual applications of Drive, Docs, or Slides work the same way as those bundled with public accounts (Amanda and Katie, 2015).

The students can access the teachers' course materials through the use of Google Drive at any time with multiple devices like Smartphone's, computers, or tablets (Google Drive, 2016). Teachers can get a drive that stores their course materials and choose to share with specific student email addresses generating from the student email list creating by the university. Teachers can choose specific student email addresses to access the course materials as "can view" option or "can edit" option. With "can view" option, the students can only view the course materials. With "can edit" option, the students would be able to upload, submit, or share files in the drive.

Amanda and Katie (2015) suggested that students generally responded favorably to the Google Drive. They are likely to have no worry about saving documents on the classroom computers due to the auto-save feature and the use of Google Drive have made collaborating on assignments easier due to the sharing capabilities. Nevertheless, limited studies have investigated the learners' learning competencies. Google Drive is offered by Google as part of its ecosystem of web based services. It provides access to data storage, a suite of office applications, synchronous editing, permissions control, and instant communications. It allows users to create and edit documents online while collaborating in real-time with other users. Google drive does not require installation and works in any popular browser/device. That is why it simplifies the learning process of the students as well as the Lecturers job, Based on this some benefits are stated below.

\section{Advantages of Google Drive}

Many new technologies and web-based activities are interactive, using the platform online coursework has the potential to create environments where students actively engage with material and learn by doing, refining their understanding as they build new knowledge (Pallof\& Pratt, (2003). Johnston, Killion\&Omomen, 2005; Driscoll (2005) observed that when students become active participants in the knowledge construction process, the focus of learning shifts from covering the curriculum to working with ideas". While students can work collaboratively in real-time, while it works across platforms (Windows, Mac, iOS and Android),and it is easy to upload and share files, Group members can chat with other collaborators and editing, it allows for exciting and engaging online peer collaboration and editing, it saves automatically every IO seconds, Educators can monitor student work easily in real-time if required, it is easy to see which students have contributed through the revision history, it is easy to export documents in various formats (RTF, PDF, HTML, MS Word and Open Office)., and it can be used with End Note and Ref Works, etc.(Alluri \& Balasubramanian, 2006)

Both students and instructors are regularly faced with a barrage of new innovative technological devices, social media tools, and educational applications. For this study, it may have appeared that Google Drive remained incorporated into the Communication course merely to ensure that this cloud computing platform could be experienced by the students (Richardson, 2009).It is important to clarify that the learning outcome for the web-based assignment was to have teacher candidates learn about effective instructional methods and co-produce and share their learning. Due to its popularity, Google Drive is a suitable and free collaboration tool for students, and can serve as a good storage area for their systems development documentation.

Rowe, Bozalek, and Frantz (2013) argued that effective group work is an essential skill for students for becoming work-ready. This technology assists them with both the technical and social aspects of their learning journey. And using technology tools 'to think with' facilitates working with ideas and learning from that process" (Scardamalia 20012). Authentic situations and scenarios can provide a stimulus for learning, creating greater student motivation and excitement for learning, representing and simulating real-world problems and contexts, providing an important structure for student thinking (Quitadamo\& Brown, 200I I). Rowe, Bozalek, and Frantz (2013) believed that the Google Drive platform, when used via a constructivist approach, has the ability to transform student learning, alter teacher-student power relationships, and facilitate critical dialogue and activities related to knowledge and authority.

\section{Roles of Google Drive on Group work Learning}

Collaborative learning is defined as a coordinated effort among team members to accomplish a shared task or common goal, can also be collaborative learning is based on the model that knowledge can be created within a population where members actively interact by sharing experiences and take on asymmetry roles (Mitnik, et el2009). Collaborative learning is a significant factor in students' learning because it promotes active learning and student-reliance in classrooms (Foote, 2009). Learning is shifting from 
passive reception to active creation. Students tend to take more ownership of their material and to think critically about related issues when they work as a team. The collaboration process enhances students' learning and develops their social skills like decision-making, conflict management, and communication (Smith \&MacGregor, 2009).

Students are increasingly using collaborative learning, an aspect of Google Dive that form part of Web 2.0 technology in their personal lives to enrich their knowledge and learning (Greenhow et al. 2009). Research into students participation patterns and usage of Google Drive is paramount to this technology becoming useful for higher education needs. Currently educational institutions remain grounded in the traditional activities and formats such as lecturing (Greenhow et al. 2009). Instructors in both higher education and secondary education worlds must be at the forefront of research observing student engagement in formal and informal learning to facilitate the use of collaborative learning as part of Google Drive platforms for educational needs.

\section{Why Google Drive Collaboration Important for Learning}

Collaboration can be defined as a coordinated, synchronous activity that is the result of an ongoing attempt to construct and maintain a shared conception of a problem (Alluri\&Balasubramanian, 2006). It has also been identified as a necessary component of active learning. The benefits of collaboration include development of critical thinking skills, problem solving skills, and discussion and consideration of ideas. Additionally, collaboration can help to understand cultural diversity and improve working with others. Social constructivist theory emphasizes the importance of collaboration in the learning process. Learning is social and requires participation in a social process of knowledge construction (Kieser\& Golden, 2009).

The tools available to communicate or collaborate with others have changed over time. Ten years ago, if a group of students needed to work outside the classroom, they would organize meetings at the library or someone's house. Today, technology offers alternative ways for students to work together in an online collaborative environment without the need to convert, saving time and money. One possible tool to support collaboration and freely available to University students is Google Drive.

\section{Google Drive Using Collaborative Learning}

McMorran (2017) felt that it is an important issue to design and allocate time on collaboration opportunities both inside and outside the classroom and it is better to collect the students email address in one master piece for easy share and edit of document and class assignment. Collaborative activities offer the following benefits:

- Encourage peer-instruction: (Mansur 1997; cf. Cain 2012): It is fairly clear that the person who learns the most is the content creator, and the one who teaches others. It is said, nothing clarifies ideas in one's mind so much as explaining them to other people. Therefore he tries to turn this to his students' advantage by assigning them with opportunities to teach each other through the act of putting ideas into their own words, students make it their "own" and ultimately learn better than just being on the receiving end.

- Building a learning community: Even if students are assigned to a arbitrary groups, by the end of the period they feel closeness to the group. The activities designed and the collaborative nature of the tools enables them to form a sense of belongings to the class as a whole.

- Give students a sense of their learning level: Students are often not quite clear on where to they stand in reference to their classmates' levels of understanding even after the mid-term. When students participate in such collaborative activities they tend to identify their strengths, their shortcomings, and what need to be improved. More importantly they are able to identify classmates to whom they can turn for help or offer their support to peers in need.

- Allow efficient time management: Students have the flexibility to work at a time that best works for them without having to bother their fellow classmates, and also have convenience of working at their own pace.

According to Common Wealth of learning (2008), teachers can share with students' movies, audio files and other learning materials through their mobile phones. Most of the mobile devices have features which can be used for recording and playing multimedia contents. Students can greatly benefit from having a camera on the cell phones for documenting visual materials and collecting scientific data (Common Wealth of learning, 2008), Cui and Wang, (2008). Despite the massive advantages that mobile devices do have in the teaching and learning process, there are some challenges of m-learning among tutors and students. Some of the mobile devices do not have programs that have direct compatibility with the academic programs such as PDF, words, excel and PowerPoint. Screen size is another limiting factor for m-learning.

\section{I0. Role of Google Drive on Study}

Google Drive is cloud-based software and storage systems that offer an online learning environment for synchronous and asynchronous interaction between students and teachers. Vecchiola, Pandey, and Buyya (2009). Argued that cloud-based services can offer educational institutions cost savings and scalability Although research on web-based, file-sharing platforms and their roles in university settings is sparse, the published, accessible research we found predominantly referred to the benefits and challenges of Google Drive. Wood (20II) found that Google Drive was an ideal way for a group of undergraduate students.It 
allows teachers and students to have dynamic and interactive learning experiences coupled with collaboration and communication (Alabbadi, 20I I).

With regard to advantages, Denton (2012) found that students enjoyed how, through Google Drive, they could share and simultaneously edit documents, while keeping a digital record of each member's contributions. File synchronization and sharing services: Cloud-based file syncing and sharing services implement automated file transfers by updating files from a dedicated sharing directory on each user's networked devices. Files placed in this folder also are typically accessible through a website and can be easily shared with other users for viewing. Such services have become popular via consumer products such as Dropbox and Google Drive.

Both students and instructors are constantly faced with a barrage of new and innovative technological gadgets, social media tools, and educational applications. For this study, it may have appeared that Google Drive was incorporated into the Communication course merely to ensure that this cloud computing platform could be experienced by the students. It is important to clarify that the learning outcome for the web-based assignment was to have teacher candidates learn about effective instructional methods and co-produce and share their learning.Students can access the educational resources they need from anywhere and at any time with any device that has internet access. Any project or educational opportunity can be scaled-up through the payment for the use of these services (Mircea \& Andreescu, 20I I).

Teachers can experience benefits from the flexibility of cloud platforms, principally the ease of preparing presentations, classes, conferences, articles, etc. Alharti, et al (2015) opined that there are many limitations such as hours of use, lack of equipment, complicated repair and maintenance, scattered locations of the laboratories, high costs of hardware and software, and contracting personnel for the IT department. Researchers can also benefit from the use of the latest technologies and hardware to perform their experiments (Shakhabubakor, 2015).

We live in a world where information is available anytime, anywhere. We not only have a computer at work and another at home, but we also likely have multiple devices like smartphones and tablets that we carry at all times (Monoz-Calle, et el 2016). With the integration of educational resources and the development of pedagogical systems, cloud computing offers opportunities to improve the quality of education, providing flexibility and accessibility through the Internet (Al-Abri et el ,2016). Significant advancements in cloud services allow individuals to connect through devices wherever, whenever. Cloud services represent one of the driving forces behind modern computing.

This fusion of intelligence and connectivity across a wide range of devices complements the scalable growth of internet services to create a new paradigm based on cloud computing. . The use of cloud computing services facilitates the implementation of social cloud ecosystems, which allows for sharing and collaboration of all varieties of resources and tools on demand with massive, ubiquitous, and open access (Luna, Castillo \&Nube, 2016). Such a paradigm would allow educational institutions, often lacking resources, to extract the maximum use of information technology, increasing the quality and accessibility of training, especially in remote areas and rural communities that have internet access (Encalada, Luis, and Seqara 2017). Cloud computing provides on-demand resources and services over a network (usually the Internet). These services are divided into three main types: infrastructure (i.e., virtual machines, servers, and storage devices), platforms (i.e., Course Builder, Moodle, and Edmodo), and software or applications (i.e., Google applications and Office 365).Students can take advantage of different learning tools available on the cloud, services such as Google Docs, Office365, and Windows.

Some universities have difficulties in providing scalable, flexible, and accessible information technology (IT) services to their students in traditional computer labs. Cloud computing services are influencing face-to-face and online education through their adoption and use. These ecosystems make it easier for universities to recreate e-learning scenarios that are conducive to the teaching of hands-on IT skills, with greater benefits than those provided by physical laboratories, thus allowing universities to concentrate more on teaching and research activities than on the implementation and configuration of complex IT software systems. The market for e-learning.

On a similar topic, the Electronic Privacy Information Center (a not-for-profit organization) filed a complaint with the American Federal Trade Commission about the security and privacy standards of Google's cloud computing, arguing that Google does not encrypt information held on itsservers (Marshall, 2009). Sultan (2010) summarized these concerns by stating that cloud computing is a rapidly developing paradigm, and many of the issues are likely to disappear as the technology matures.

Many scholars highlight the disconcerting aspects of private cloud storage systems within the realm of education and public sectors. Predominantly, these issues focus on dependency, security, and privacy (Archer et al., 2010; Owens, 2010; Rosenthal et al., 2010)Mearian, 2012; Sultan (2010) explained that some executives in the Information Technological sector view many web-based platforms as a trap aimed at forcing people to become dependent on proprietary, corporate systems and their services that will likely prove to be a financial burden in the future. Security challenges associated with any off-hosting site of data and services (i.e., cloud-based services) revolve around questions about who can access customer data and what are the security policy perimeters with the host company? (Willcocks, Venters, Whitley, 20I4). 


\section{Role of Google Drive on Upload/Download of Files}

Anytime, anywhere, with any tool connected to the Internet. In turn, web-based file-sharing tools have become an integral part of the modern, mobile lives of many students. These collaborative web-based technologies have triggered a wave of free online wikis, word documents, spreadsheets, presentations, and discussion forum software (Fullan, 20I3; Preston. in press; Rienzo\& Han, 2009). Consequently, using these applications as a communicative tool and collaborative learning platform is gaining popularity among university instructors. Socially constructed knowledge is information that is co-produced and shared by and between its creators. Rowe, Bozalek, and Frantz (2013) believed that the Google Drive platform, when used via a constructivist approach, has the ability to transform student learning, alter teacher-student power relationships, and facilitate critical dialogue and activities related to knowledge and authority. Although research on web-based, file-sharing platforms and their roles in university settings is sparse, the published, accessible research we found predominantly referred to the benefits and challenges of Google Drive.

With regard to advantages, Wood (201I) found that Google Drive was an ideal way for a group of undergraduate physics students to complete lab reports, where each student in the lab group was responsible for writing parts of the introduction, procedure, analysis, results, theory, and conclusion. Denton (2012) found that students enjoyed how, through Google Drive, they could share and simultaneously edit documents, while keeping a digital record of each member's contributions.. Likewise, Spaeth Sinex and Chambers (2013) described how college-level science students successfully used Google Drive on group laboratory assignments, where each of the students input data to the shared spreadsheet and Black (2012) and. With regard to B.Ed. student experiences with Google Drive, Donna and Miller (20I3) found that teacher candidates had reservations about the time needed to learn cloud computing technologies and that this online medium mitigated aspects of face-to-face collaboration. In this same study, teacher candidates expressed concerns about peers potentially making inappropriate comments within the shared documents,.

\section{I2. Methodology of the Study}

The targeted population of this study comprises all the 263 students in 300 Level students in the three Universities offering Business Education programme. The instrument for the data collection was self structured questionnaire. The questionnaire was structured in 4 points rating of Highly Preferred (HP), Moderately Preferred (MP), Low Preferred (LP) and Not Preferred (NP). The breakdown of the questionnaire items base on research questions was as follows: Questionnaire Item I of I-I2 was used to address research question one. Item I 3 to 24 were used to answer research question two while item 25 to 36 were used to address research question three.

Reliability of an instrument is the measure of the extent to which a research instrument yields consistent results or data after repeated trials during the study (Sambo 2008). Reliability will measure the relevance and correctness of the instruments (Mugenda and Mugenda, 2003). The reliability of the instrument was determined using Cronbach alpha where a reliability coefficient 0.08 was obtained indicating that the instrument was reliable.

\section{Presentation of Results}

The result presented here is based on the research questions formed to guide the study.

\section{Research Question One}

What is the undergraduate business education students' preference on the use of Google drive as an assignment/group work platform for learning in north- east Nigeria?

The result of items used to answer research question one in Table I range from 3.39 to 3.1 I which were within the index score for agreed. The mean score of four of the items were found to be below the 2.50 mean score for agreed. The Grand mean obtained was greater than the index mean score $2.94>2.50$. The result therefore revealed that the reference on the usage of Google Drive platform for assessment among undergraduate business education students was positive.

Table I: Students' preference on the use of Google drive as an assignment/group work platform for learning

\begin{tabular}{clccc}
\hline S/NO & \multicolumn{1}{c}{ VARIABLE } & MEAN & SD & DECISION \\
\hline I & Using Google drive for group work & 3.39 & 0.843 & Agree \\
\hline 2 & I like commenting on others' contributions to group work in Google drive & 3.25 & 0.842 & Agree \\
\hline 3 & I like editing others' contributions to group work in Google drive & 2.39 & 0.98 & Disagree \\
\hline 4 & I like that other students comment on my work in a group on Google drive & 3.21 & 0.925 & Agree \\
\hline 5 & I like other students to edit my own work in the group on Google drive & 3.19 & 0.964 & Agree \\
\hline 6 & The quality of collaboration in the group increases with the use of Google drive & 2.43 & I.036 & Disagree \\
\hline 7 & $\begin{array}{l}\text { Google drive motivated me to collaborate with fellow students in a group } \\
\text { learning }\end{array}$ & 2.40 & I.037 & Disagree \\
\hline 8 & I like Google drive because it works as expected as a collaborative platform & 2.26 & I.048 & Disagree \\
\hline
\end{tabular}




\begin{tabular}{clccc}
\hline 9 & $\begin{array}{l}\text { I like how Google drive usages in learning is gradually replacing use of human } \\
\text { labour in a classroom }\end{array}$ & 3.22 & 0.932 & Agree \\
\hline I0 & Students find it easy to use Google drive & 3.3 & 0.867 & Agree \\
\hline II & Google drive face serious challenges when there is inter connectivity problem. & $3.1 \mathrm{I}$ & 0.989 & Agree \\
\hline I2 & I like how a Collaborative activity is gradually replacing interpersonal contacts. & 3.17 & 0.94 & Agree \\
\hline & Grand Mean & 2.94 & 0.95 & Agree \\
\hline & Source: Field Survey (20I8)
\end{tabular}

\section{Research Question Two}

To what extent is the undergraduate business education students' preference on the use of Google drive as a platform for study in north east Nigeria?

The mean score of 12 Questions was to answer research question two in Table 2, range from 3.32 to 2.20 with standard deviation of $0.89 \mathrm{I}$ and 1.06 respectively. The grand mean obtained (2.97) was greater than the index mean score of 2.50 for agree. The result therefore shows that the reference of undergraduate business education students have on the Google Drive platform for learning was positive.

Table 2: Responses on students' preference on the use of Google Drive as a learning platform for study

\begin{tabular}{|c|c|c|c|c|}
\hline S/No & Questionnaire items & Mean & 'SD & Decision \\
\hline 13 & $\begin{array}{l}\text { I like the relatively large option storage allowing of Google drive very useful for saving } \\
\text { data (e.g. Files, folders, etc.). }\end{array}$ & 3.32 & $0.89 \mathrm{I}$ & Agree \\
\hline $\mathrm{I} 4$ & It is easy to store data on Google drive & 3.I I & 0.947 & Agree \\
\hline I5 & It is easy to retrieve data stored in Google drive & 3.05 & 1.003 & Agree \\
\hline 16 & I find data storage on Google drive very interesting & 3.23 & 0.887 & Agree \\
\hline 17 & Google drive provides easy access between lecturer and student. & 3.I I & 0.949 & Agree \\
\hline I8 & I face serious challenges to store information when there is inter connectivity problem. & 2.37 & 0.99 & Disagree \\
\hline 19 & To store data becomes impossible where network is not available. & 2.48 & 1.057 & Disagree \\
\hline 20 & I find data storage on Google drive very difficult & 2.20 & 1.06 & Disagree \\
\hline $2 \mathrm{I}$ & $\begin{array}{l}\text { Google drive give room for storing large volume of learning materials within a short } \\
\text { period of time. }\end{array}$ & 3.19 & 0.885 & Agree \\
\hline 22 & $\begin{array}{l}\text { I like the way Google drive provides opportunities to store new knowledge for academic } \\
\text { purpose. }\end{array}$ & 3.12 & 1.017 & Agree \\
\hline 23 & I find data storage on Google drive very easy & 3.26 & 0.906 & Agree \\
\hline \multirow[t]{2}{*}{24} & Using Google Drive storage enhance my academic performance & 3.17 & 0.94 & Agree \\
\hline & Grand Mean & 2.97 & 0.961 & Agree \\
\hline
\end{tabular}

Source: Field Survey (2018

\section{Research Question Three}

What is Undergraduate business education students' preference on the use of Google drive as a platform for uploading and downloading files in north east Nigeria?

From Table 3, the mean scores ranging from (3.05 to 3.26) which indicates that the responses were within the index score for agree. While the mean score that falls between 2.20 to 2.48 found to be below 2.50 mean score index for agree. The grand mean stood at $2.60>2.50$. The result thus indicates that the preference on the use of Google Drive platform for upload/download of files among undergraduate business education students was positive.

Table 3: Responses on students' preference on the use of Google Drive as a platform for upload/Download of files

\begin{tabular}{|c|c|c|c|c|}
\hline $\mathrm{S} / \mathrm{NO}$ & Questionnaire item & Mean & $\mathrm{SD}$ & Dec \\
\hline I & I like using Google drive platform for sharing student materials & 3.26 & 0.906 & Agree \\
\hline 2 & I like using Google drive platform for sharing materials gotten from my Lecturers & $3 . \mathrm{II}$ & 0.947 & Agree \\
\hline 3 & $\begin{array}{l}\text { I like the sharing folder option of Google drive because it enables me to access my } \\
\text { resources lecture notes }\end{array}$ & 3.05 & 1.003 & Agree \\
\hline 4 & $\begin{array}{l}\text { I like the sharing folder option of Google drive because it enables me to access my } \\
\text { resources Video }\end{array}$ & 3.23 & 0.887 & Agree \\
\hline
\end{tabular}




\begin{tabular}{clrrr}
\hline 5 & $\begin{array}{l}\text { I like preview of the files shared on Google drive from the platform is useful to check } \\
\text { before downloading }\end{array}$ & 3.I I & 0.949 & Agree \\
\hline 6 & I like the "filter by posts" search option sharing option of Google drive & 2.37 & 990 & Disagree \\
\hline 7 & Students find it easy to share file using Google drive & 2.48 & I.057 & Disagree \\
\hline 8 & Students find it difficult to share file using Google drive & 2.20 & I.06 & Disagree \\
\hline 9 & I like Google Drive because of its 'send links' instead of file attachment feature & 3.19 & 0.825 & Agree \\
\hline I0 & I like Google Drive because of its quick formatting feature & 3.12 & I.0I7 & Agree \\
\hline II & I like Google Drive because of its clear formatting feature & 3.08 & 0.949 & Agree \\
\hline I2 & I find it difficult to download materials from the Google Drive & 2.27 & I.I45 & Disagree \\
\hline & Grand Mean & 2.60 & 0.978 & Agree \\
\hline
\end{tabular}

Source: Field Survey (2018)

Mean and standard deviation are computed on the data collected from the field; the result is presented in the table above.

From Table 3 the respondents for all the items have the mean scores ranging from (3. 36 to 3.00) which indicates that all the respondents have agreed. The table shows the responses for all the items and they are above the mean cut-off point for the study, thus, the decision agrees or disagrees on the table. This means that greater respondents agreed with all the items as they are opportunities for using Google Drive as learning platform.

\section{Discussion of the Result}

The study examined the Business Education undergraduate student's preference toward the usage of Google Drive for academic purpose. The study discovered that the students use Google Drive to advance their learning efforts in digital world, and recognize changes in technology, understand assignment/group work trends, to comprehend storage problems and nitty and gritty for loading and uploading information. The findings of research Question One was in line with the view that assignment/group work is characterized by positive interdependence, where students perceive that better performance by individuals produces better performance by the entire group (Johnson, et al., 2014). And also Sharp (2009) argued that Google Drive is easy and fast tool that is well-suitable for facilitating digital writing workshops that combine peer editing with cooperative grouping and small group fine-tuned writing instruction. Evans and McKee (2010) observed that the use of social media technologies provide insight and ideas on innovative ways to serve learners better. And also in respect of the benefits of using Google Drive by undergraduate business education students Preference for assignment/group work. The responses gathered from the questionnaire revealed the benefits of using Google Drive for learning activities is one of the effective way of quick perception by business education students in showing their preference for learning purposes.

The research questions two indicate benefit drive by business education student by using Google Drive for study to get more relevant materials for their learning. There are many opportunities in using Google Drive as student may gain more in the interactions for wider knowledge in their learning in the business education studies. The research questions three indicates that the business education preference in Google Drive explore the students by uploading/downloading of files to guide them in their learning. Google Drive help students to communicate so easy so that they can solve their academic challenges by contributing on the current matter to use different ideas from different students that are partaking in an interactive session that comprise many students with different level of intelligence. Google Drive also widens students' maturity in term of modern/electronic learning that can combine people from different part of the world to have preference to common ground. The students submission of the same materials on the issue of group work making it so common for students to be more reluctant on the study as they relied on their colleagues to make all the necessary work, this type of group work is formally termed supportive learning, and is defined as the instructional use of small groups to promote students working together to maximize their own and each other's learning (Johnson, et al., 2008). It is also gradually replacing interpersonal contacts between teachers and students that make things difficult in the event of learning outcome. The findings revealed that one of the challenges of using Google Drive to include other sites that are not relevant to the studies such as bad videos and pictures sites that might divert the attention of students from the studies. Baran (2012) also stated that technology is a double edge sword; it power for bad and good resides in the users. More so, communication becomes impossible where network is not available. There are serious challenges when there is interconnectivity problem. All gadgets used to access Google Drive like Handset, laptop or Ipad are required internet connection. Thus, Google Drive may not be in reached to the poor students.

Conclusion

The results obtained from this study show that a reasonable number of undergraduate business education students of north-eastern university's use Google drive as learning platform that enhance student's performance. Google drive functions i.e collaborating learning, file storage, file sharing and as platform for learning has tremendous benefits as far as enhancing learning activities for university students have been confirmed from the findings of this study. Finally, from the results of this study, the 
researcher saw a reason why a famous scholar argued that technology can be used in ways beneficial or otherwise. Technology is a double-edged sword. Its power for bad and good resides in the users (Flanigan \& Kiewra, 2018;Margaret, Uma, Tejonidhi\&Neelakantappa,2018; Temple, Ogle, Crawford \& Freppon, 20I8). Based on this, it is very imperative to note that the relevant university authorities have to take measures to ensure that the students use Google drive for academic activities in order to enhance the students' academic performance.

\section{Reference}

Albergotti, Reed; MacMillan, Douglas; Rusli, Evelyn M. ( 20I4). Facebook's \$I9 Billion Deal Sets High Bar. The Wall Street Journal.pp. AI, A6.

Al-Tarawneh, H. A. (2014). The influence of social networks on students' performance. Journal of Emerging Trends in Computing and Information Sciences, 5(3), 200-205.

Amanda, I. and Katie, L. L., (2015). Google classroom for librarians: features and opportunities. Library Hi Tech News, Vol. 32, pp. I-3.

Beleviciute I., Sileikiene A., Integrating Learning Management and Knowledge Management Systems, Proceedings of the

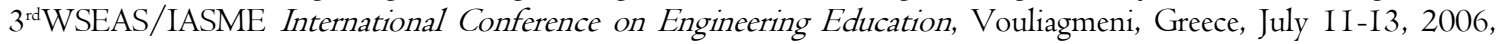
pp. I08-II3.

Brown, L. (2008). Using Mobile Learning to Teach Reading to Ninth-Grade Students, Ph.D dissertation Capella University, USA. Available online at http://gradworks.umi.com/3330949.pdf

Burstein, H. J., Elias, A. D., Rugo, H. S., Cobleigh, M. A., Wolff, A. C., Eisenberg, P. D., ... \& Baum, C. M. (2008). Phase II study of sunitinib malate, an oral multitargeted tyrosine kinase inhibitor, in patients with metastatic breast cancer previously treated with an anthracycline and a taxane. Journal of Clinical Oncology, 26(II), I8I0-I8I6.

Chinnery, G. (2008). ON THE NET You've Got some GALL: Google-Assisted Language Learning. Language Learning and Technology, I2(I), 3-II.

Conner, N. (2008).Google Apps: The missing manual. Sebastopol, CA: O’Relly Media.

Connolly, C., \& Lam-Knott, S. Category Archives: Vernacular City.

Davis F. D. (1989). Perceived usefulness, perceived ease of use and user acceptance of information technology.MIS Quarterly, I3(3): $319-339$.

Dietz-Uhler,B. \& Bishop-Clark,C (200I) The use of computer mediated communication to enhance learning.

Dillenbourg, P., Järvelä, S., \& Fischer, F. (2009). The evolution of research on computer-supported collaborative learning. In Technology-enhanced learning (pp. 3-I9). Springer, Dordrecht.

Denton, D. W. (2012). Enhancing instruction through constructivism, cooperative learning, and cloud computing. TechTrends, 56(4), 34-4I.

Foote, E. (2009). Collaborative Learning in Community College.Retrieved April 20, 20I I, fromhttp://www.ericdigests.org /I998-I/ colleges.htm>.

Fullan, M. (2013). Stratosphere: Integrating technology, pedagogy, and change knowledge. Toronto, ON: Pearson.

Gilmore, C., \& Halcomb, C. G. (2004). Technology in the classroom: Investigating the effect on the student-teacher interaction. Usability News, 6(2).

Gremm, J., Barth, J., Fietkiewicz, K. J., \& Stock, W. G. (2018).Knowledge Economy and Knowledge-Based Development.In Transitioning Towards a Knowledge Society (pp. 69-74).Springer, Cham.

Greeenhow, C., and Robelia, E. (2009). Old communication, new literacies; social networking sites as social learning resources.Journal of computer mediated communication, I4(4), I I30-I I6I

Google drive (2016). A safe place for all your files [online]. Retrieved July I, 2016 from web site: http://www.google.com/int/en/drive/.

Hammond, M (2000) Communications within online forums: The opportunities, the constraints, and the value of communicative approach, Computers and Education, 35: 25I-262.

Hong, F. Y., Chiu, S. I., \& Lin, H. Y. (2012). The development and current states of private college student mobile phone addiction scale. Chung Cheng Educational Studies, II(I), 87-II6.

Hoppe, M.(2009). Mobile learning and Education application.www.pervasive.Retrived October 3I,2012 from wiwi.unidue de/.../hoppe mobile-and-educ

Ishtaiwa, F. F., \& Aburezeq, I. M. (2015). The impact of Google Docs on student collaboration: a UAE case study. Learning, Culture and Social Interaction, 7, 85-96.

Izenstark, A., \& Leahy, K. L. (2015). Google classroom for librarians: features and opportunities. Library Hi Tech News, 32(9), I-3.

Kafyulilo, A.(2012). Access, use and perceptions of teachers and students towards mobile phones as a tool for teaching and learning in Tanzania. Retrieved October 3I, 2012 from http//rd.springer.com/article/I0.I007/sI0639_012_9207-vEducational and information technologies journal 
Karasavvidis, I., Pieters, J. M., \& Plomp, T. (2003). Exploring the mechanisms through which computers contribute to learning. Journal of Computer Assisted Learning, I9(I), I I5-I28.

Kizito,N.R, (20I2). Pre testing Mathematical Concept with the mobile phone implications for Curriculum Design, Retrieved October 3I, 2012 from http://www.irrodi.org/index.php/article/view/I065/2075.

Lee T.H. Shen P.K. Tsai C.L. Applying Web-Enabled problem-based and self-Regulated learning to involve low achieving students in learning application software, proceedings of the $8^{\text {th }}$ WSEAS International Conference on Mathematics and Computer in Business and Economics, Vancouver, Canada June, I9-2I,2003, pp2I9-225

López, O. E. H., Espinosa, Á. A. D., \& Cruz, A. V. Introducing the Knowledge Building pedagogy in Kindergarten Summer Institute 2010 OISE-University of Toronto.

Lusk, B. (2010) Digital Natives and Social Media Behaviors: An Overview, The Prevention Research, Vol.I7, pp3-6

Mahajan, P. S. (2018). Marketing strategy of a company using shared economy business model. The case of "Airbnb".

Miller, D. (2011). Miller (1983) Revisited: A reflection on EO research and some suggestions for the future. Entrepreneurship theory and practice, 35(5), 873-894

Miller, D. (2013). A reflection on EO research and some suggestions for the future. Entrepreneurship theory and practice, 35(5), 873-894

Mitnik, R., Recabarren, M., Nussbaum, M., \& Soto, A. (2009). Collaborative Robotic Instruction: A Graph Teaching Experience. Computers \& Education, 53(2), 330-342.

Moats, J. B. (2013). A Close Look at Technology Acceptance: A Phenomenological Study (Doctoral dissertation).

Pasek\&Hargittai (2009). Facebook and academic performance: Reconciling a media sensation with data. First Monday I4(54).

Pinchai,Sundar (2012) " Introducing Google Drive....Yes, Really.”

Perron, B., \& Sellers, J. (20II).A review of the collaborative and sharing aspects of Google Docs.ResearchonSocial Work Practice, 2I, 489-490.

Prensky, M. (200I). Digital natives, digital immigrants, on the horizon, 9 (5), (online)available. http://www.marcprensky.com/writting/prensky (February I2, 20I I)

Richardson, W. (2009). Blogs, wikis, podcasts, and other powerful web tools forclassrooms (2nd ed). Thousand Oaks, CA: Corwin Press.

Rienzo, T., \& Han, R. (2009). Microsoft or Google Web 2.0 tools for course management. Journal of Information Systems, 20(2), I23-I27.

Rowe, M., Bozalek, V., Frantz, J. (2013).Using Google Drive to facilitate a blended approach to authentic learning.British Journal of Educational Technology, 44(4), 594-606. dio:I0.I I I I/bjet.I2063

Roreger, H., \& Schmidt, T. C. (2012, March). Role of Facebook on e-learning

Prasertsith, K., Kanthawongs, P., \& Limpachote, T. (2016). Students' Google Drive Intended Usage: A Case Study of Mathematics Courses in Bangkok University. International Association for Development of the Information Society.

Preston, J. P., Jakubiec, B. A., Jones, J., Earl, R., DesRoches, A., MacKenzie, K., ... \& Christensen, R. (2015). Web-Based FileSharing in a Bachelor of Education Program: Transformational Learning. Transformative Dialogues: Teaching \& Learning Journal, 8(I).

Sambo, A. A. (2005), Research Method in Education. Stirling-Horden publishers Nigeria Ltd Ibadan.

Sharp, V. (2009).Computer education for teachers: Integrating technology into classroom teaching (6th ed).Hoboken, N.J.: John Wiley.

Suwantarathip, O., \& Wichadee, S. (20I4). The Effects of Collaborative Writing Activity Using Google Docs on Students' Writing Abilities. Turkish Online Journal of Educational Technology-TOJET, I3(2), I48-I56.

Seely Brown, J., \& Adler, R. P. (2008). Open education, the long tail, and learning 2.0. Educause review, 43(I), I6-20.

Smart, K. L., \& Cappel, J. J. (2006). Students' perceptions of online learning: A comparative study. Journal of Information Technology Education: Research, 5(I), 20I-219.

Smith, B. L., \&MacGregor, J. T. (2009). What is collaborative learning? National Center on PostsecondaryTeaching, Learning and Assessment at Pennsylvania State University. Retrieved April 3, 20II, fromhttp://learningcommons.evergreen.edu/pdf/collab.pdf

Wood, M. (20II). Collaborative lab reports with Google docs. The Physics Teacher, 49(3), I58-I59. dio:IO.III9/I.355550I

\section{Copyrights}

Copyright for this article is retained by the author(s), with first publication rights granted to the journal. This is an open-access article distributed under the terms and conditions of the Creative Commons Attribution license (http://creativecommons.org/licenses/by/4.0/). 